\title{
Folk Wisdom About the Effects of Relationship Conflict
}

\author{
Jeffrey Sanchez-Burks, ${ }^{1}$ Eric J. Neuman, ${ }^{1}$ Oscar Ybarra, ${ }^{2}$ Shirli Kopelman, ${ }^{1}$ \\ Hyekyung Park, ${ }^{2}$ and Karen $\mathrm{Goh}^{3}$ \\ 1 Ross School of Business, University of Michigan, Ann Arbor, MI, U.S.A. \\ 2 Department of Psychology, University of Michigan, Ann Arbor, MI, U.S.A. \\ 3 Marshall School of Business, University of Southern California, Los Angeles, CA, U.S.A.
}

\section{Keywords \\ culture, conflict, conflict frames, protestant relational ideology, American exceptionalism, holistic thinking.}

\section{Correspondence}

Jeffrey Sanchez-Burks, Ross School of Business, University of Michigan, 701 Tappan Street, Ann Arbor, Ml 48109-1234, U.S.A.; e-mail: jsanchezburks@ umich.edu.

\begin{abstract}
Three experiments examined cultural differences and similarities in folk wisdom about the effects of perceived conflict. In Study 1, Americans exhibited an optimistic bias relative to East Asians in their beliefs about perceived relationship conflict, but not conflict in general. Study 2 suggests that these findings cannot be accounted for by cultural differences in perceptions about the distinction, or lack thereof, between relationship and task-focused forms of conflict. Furthermore, the results demonstrated an interaction effect such that both groups prefer to address and resolve perceived task conflict proactively, whereas only European Americans perceive that it is relatively unnecessary to address relationship conflict to achieve task performance. Study 3 suggests that these cultural patterns have behavioral implications, such that Americans were more likely than East Asians to join a talented group likely to experience relationship conflict. Together, these results suggest novel implications for intragroup dynamics in intercultural contexts.
\end{abstract}

From the time of Tocqueville (1840) to the present, observers of American culture have remarked that despite being highly individualistic, Americans exhibit a penchant for working in groups (e.g., Bellah, Madsen, Sullivan, Swidler, \& Tipton, 1996). Coupled with a belief that a strong work ethic is a sufficient condition for success (Furnham, 1990), Americans may be particularly optimistic about the ability for a hard working group to accomplish its task objectives (cf. Earley, 1993). As ample research has shown, however, a number of factors can impede a group's success. One of the most reliable and well-understood contributors to suboptimal group performance is relationship conflict,

The first two authors contributed equally to this article. 
conceptualized in prior research as disagreements and interpersonal friction rooted in personal and social differences unrelated to a team's work (De Dreu \& Van Vianen, 2001; Jehn, 1995; Simons \& Peterson, 2000). In a recent meta-analysis by De Dreu and Weingart (2003) and a comprehensive theoretical model by Jehn and Bendersky (2003), relationship conflict in workgroups is uniformly associated with negative outcomes.

Complementary to this research on the empirical consequences of conflict, scholars have begun to examine folk wisdom (i.e., lay beliefs and assumptions that exist within a culture) about conflict and its consequences (Jehn, Rupert, \& Nauta, 2006; Pinkley, 1990). Folk wisdom about conflict refers to beliefs and intuitions about conflict and its likely effects on a group. This article examines evidence that folk wisdom about the outcomes of relationship conflict differs in theoretically interesting ways from empirical consequences established in the literature. Our theoretical and empirical focus builds upon recent research by Gelfand et al. (2001), who suggest that folk wisdom about conflict may vary across cultures to the extent that such folk wisdom reflects deep-seated cultural assumptions and ideologies about the interpersonal dimension of workplace interactions. In this way, conflict-based folk wisdom research contributes to the impressive extant literature on conflict's consequences by revealing the diversity in a priori beliefs and perceptions about conflict that can affect group dynamics (e.g., Jehn \& Chatman, 2000).

Distinguishing folk wisdom about relationship conflict from empirical accounts of its consequences naturally raises the issue of correspondence between perceived effects and empirically established effects. However, given the robust and uniformly negative effect of relationship conflict on groups, it would not be surprising to find a close correspondence between folk wisdom and this straightforward empirical pattern. To not agree that relationship conflict necessarily hampers task success requires an underlying assumption that interpersonal and emotional concerns are relatively unimportant in work contexts.

Recent research on the attributes of American workways (Sanchez-Burks, 2005) suggests such a deviation actually may be present in the United States (Morris \& Gelfand, 2004). Research on American workways has revealed a unique folk wisdom about the relative unimportance of the relational dimension of workplace interactions that may be informative to the psychology of American folk wisdom about relationship conflict. Specifically, if this folk wisdom has implications for how people view conflict, it would suggest that Americans may be less skeptical about the negative influence of relationship conflict than would be warranted based on empirical research. In addition to this discrepancy, such a deviation on the part of Americans would be interesting because the evidence supporting the negative impact of relationship conflict has been collected primarily in the United States.

Research on cultural folk wisdom about relationship conflict, conducted primarily within the context of negotiations, has revealed deep-seated variation in cognitive representations of conflict (e.g., Doucet \& Jehn, 1997; Gelfand \& Brett, 2004; Pinkley, 1990). This shift to understanding beliefs about conflict, in contrast to its actual consequences or frequency across cultures (e.g., Rahim, Antonioni, Krumov, \& Ilieva, 2000; Tinsley \& Brett, 2001; Tjosvold, Poon, \& Yu, 2005; Weldon \& Jehn, 1995) has proved useful in 
understanding how cognitions shape decision making and behaviors in conflict situations. For example, whereas Americans perceive negotiation as an impersonal, taskfocused interaction creating winners and losers, the Japanese more commonly perceive negotiation as conflict centered on the principle of compromise (Gelfand et al., 2001). These differences in turn influence each party's strategy, outcome preferences, and evaluations of other negotiating parties (Gelfand et al., 2002). Thus, folk wisdom about conflict, developed through social-cultural experiences, is a mechanism through which culture influences perceptions and reactions to conflict (Gabrielidis, Stephan, Ybarra, Pearson, \& Villareal, 1997).

Extending beyond the context of negotiation, the present research focuses more broadly on cultural-based cognitions about the consequences of relationship conflict in teams, as well as behavioral intentions regarding the prospect of working with a group likely to experience relationship conflict. To assess what features of these cognitions are specific to relationship conflict as opposed to conflict in general, the research also assesses beliefs and reactions to another form of conflict, namely task conflict. The disagreements and tensions that can influence a group's ability to perform well can be differentiated, at least conceptually, by whether they concern the task at hand or relational issues (Clark \& Mills, 1993; Coser, 1956; Jehn, 1995). For example, disagreements about which of two grant-funding opportunities a laboratory should pursue, or how a team will market a product, are examples of task conflict, which arise from differing ideas and opinions among group members. Groups also can disagree on relational concerns unrelated to the designated task. A relationship conflict arises from interpersonal incompatibilities and friction among group members (Jehn \& Mannix, 2001).

Empirically, the relative consequences of intragroup relationship and task conflict have received much attention. Although task and relationship conflict can co-occur (e.g., Simons \& Peterson, 2000; Tidd, McIntyre, \& Friedman, 2004), the seminal research by Jehn and Bendersky (2003) identified important distinctions between each type of conflict and suggested that task conflict may be helpful to groups, for example, by facilitating members to analyze critically their work and explore all alternatives (see also Amason, 1996; Nemeth, 1986; Tjosvold, 1991; Triandis, Marin, Lisansky, \& Betancourt, 1984). However, task conflict has been found to harm group performance when it interferes with routine work (Jehn, 1995), when the group members lack trust in one another (Peterson \& Behfar, 2003), or when it degenerates into relationship conflict (Jehn, 1995). The potential good that could result from task conflict is actually more bleak according to De Dreu and Weingart (2003), who provide meta-analytic evidence showing that overall task conflict is detrimental to team processes and performance (see Jehn and Bendersky (2003) for a discussion on moderators of the task conflict-outcome link).

Although there remains a lively (and task-focused) debate concerning the conditions under which task conflict might be beneficial to groups (e.g., Jehn, Northcraft, \& Neale, 1999), there is a rare unanimity about the consequences of relationship conflict. In virtually every instance examined empirically, the emergence of relationship conflict has been shown to be detrimental to performance (De Dreu \& Weingart, 2003). The harm 
induced by relationship conflict appears at both the individual and group level (Jehn \& Bendersky, 2003) and includes reduced productivity (Wall \& Nolan, 1986), reduced creativity (Amabile, Conti, Coon, Lazenby, \& Herron, 1996), and reduced satisfaction within the group (Jehn et al., 1999). Together, these studies show that whereas information about the presence of task conflict may not always be sufficient to predict a team's ability to accomplish its task, information about the presence of relationship conflict should provide highly diagnostic information about its ability to perform well (Amason \& Sapienza, 1997; Cosier \& Rose, 1977; Evan, 1965; Guetzkow \& Gyr, 1954; Pelled, 1996; Pinkley, 1990; Wall \& Nolan, 1986).

Indeed, given the likelihood that workgroups will experience relationship conflict, it is highly unlikely that a cultural group would not recognize how such conflict reliably limits a team's ability to succeed. Maintaining such disbelief regarding the effects of relationship conflict would require a group to give far less weight to relational concerns over task concerns in estimating the factors that predict project performance. Yet this possibility may not be far-fetched in light of culture and cognition research showing that there are deep-seated ideological assumptions about the unimportance of relational concerns in organizations, particularly within European American society (for a review, see Sanchez-Burks, 2005). The present research examines decision makers' folk wisdom about the outcomes of relationship conflict.

There is a rich literature in social psychology showing substantial variation in the folk wisdom cultural groups use to understand and navigate social interactions at work (e.g., Fiske, Kitayama, Markus, \& Nisbett, 1998; Hui \& Luk, 1997; Sanchez-Burks \& Lee, 2007). A common theme is the diverse way in which interpersonal harmony in social and work settings is maintained through complex beliefs, norms, and institutions. Despite substantive differences in relational practices and traditions, the modal tendency within this global distribution appears to be an emphasis on the social-emotional dimension, save for one consistent exception-mainstream American culture (SanchezBurks, 2005; Smith, Peterson, \& Schwartz, 2002).

The importance of relational concerns is heightened at work in cultures such as Korea, where relationships, based on the notion of chaebol or company familialism, are maintained by a heightened attunement to interpersonal relations within the collective (Ambady, Koo, Lee, \& Rosenthal, 1996; Kim, 1988); in China, where the cultural value of maintaining a strong, dense network of relationships in business, captured in the constructs you-yi and quanxi, requires ongoing sensitivity to both the structural and social-emotional dimension of interpersonal relationships (Farh, Tsui, Xin, \& Cheng, 1998; Li, Tsui, \& Weldon, 2000); and Mexico, where an emphasis on simpatía is manifested in attention given to both the task and on maintaining social harmony (Triandis et al., 1984).

An opposite pattern is found within cultures steeped in Protestant Relational Ideology (PRI), such as European American culture (Sanchez-Burks, 2005). This ideology is characterized by a cognitive orientation where work contexts tend to activate schemas that diminish the importance of and attention to the relational dimension of the situation. We draw on PRI theory and prior empirical research on this American ideology as a lens to understand expectations about conflict. Paradoxically, applying PRI to the 
domain of folk wisdom about conflict suggests the hypothesis that it may be quite rational-perhaps even commonsensical-for Americans to believe that relationship conflict does not necessarily hinder a group's performance. Thus, cultural analyses of East Asian societies such as in Korea and China, which demonstrate stronger beliefs about the importance of relational dynamics, suggest a closer match between East Asian folk wisdom about conflict and empirical evidence of the actual consequences of relational conflict. In contrast, cultural analyses of American culture suggest the potential for an asymmetry in conflict beliefs vis-à-vis these empirical findings. Given this potential for an American rather than an East Asian asymmetry in conflict beliefs, we develop specific hypotheses about cultural similarities and differences in conflict expectations and corresponding behavioral intentions.

Protestant Relational Ideology theory describes a unique feature of American culture that influences the development and accessibility of relational schemas used to navigate work compared to nonwork social interactions. Sociological, historical, and psychological research links PRI to the beliefs and practices of the founding Protestant communities of European American society (McNeill, 1954; Sanchez-Burks, 2005; Weber, 1947). Although originally tied to explicit religious connotations reflecting proper behavior, beliefs about the importance of restricting relational concerns while working were secularized and incorporated into the contemporary work ethos of European American culture (Fischer, 1989; Lenski, 1963; Weber, 1904).

Cognitive and behavioral evidence for PRI suggests that within work contexts, European Americans show impoverished recall for interpersonal information relative to task-related information (Sanchez-Burks, 2005). Americans also exhibit a tendency to reason that effort spent maintaining interpersonal work dynamics necessarily limits a team's ability to accomplish task objectives (Sanchez-Burks, Nisbett, \& Ybarra, 2000). They also demonstrate lower levels of nonconscious behavior indicative of relational attunement (i.e., behavioral mirroring), lower levels of attention to relational cues in communication at work compared to nonwork contexts (Sanchez-Burks et al., 2003), and they attend less to subordinates' intrinsic motivations at work (DeVoe \& Iyengar, 2004). Together these studies suggest that for Americans in general, and for European Americans in particular, work settings activate relational schemas that diminish the importance of relational concerns.

To examine whether there is evidence of PRI manifested in folk wisdom about relationship conflict, we conducted three cross-cultural experiments. Study 1 examined whether Americans indeed exhibit an optimistic bias (i.e., less concerned about its effects) in their beliefs about relationship conflict. Study 2 tested whether this pattern could be alternatively explained by cultural differences in perceptions about the distinction-or lack thereof-between relationship and task conflict. In Study 2 we do not address the ongoing debate about whether these types of conflict are theoretically or empirically distinct (for a through discussion, see De Dreu \& Weingart, 2003; Jehn \& Bendersky, 2003; Simons \& Peterson, 2000). Rather we focus on lay beliefs about whether each form of conflict can be evaluated separately. Finally, Study 3 tested whether cultural differences in folk wisdom about relationship conflict have behavioral implications. 


\section{Study 1}

We conducted a survey study in which respondents reported whether or not they agree that different forms of conflict necessarily have a negative effect on intragroup outcomes. According to PRI theory, differences in the importance given to relational versus task concerns at work within the United States suggest the following within-culture hypothesis: Americans will perceive relationship conflict as less detrimental to workgroup performance than nonrelationally based conflict such as task conflict-a pattern that would be at odds with many analyses of the actual consequences of conflict. With regard to between-culture patterns of conflict expectations, these should depend on the type of conflict considered. Whereas research has not found East-West differences in beliefs about the importance of task-objectives at work, there is much evidence to suggest differences in beliefs about the importance of the relational dimension of work (Sanchez-Burks \& Lee, 2007). In East Asian societies (e.g., Korean, China), there is a tendency to afford equal or greater importance to relational concerns at work in contrast to the diminished importance regarded to these concerns by Americans (e.g., Ambady et al., 1996; Farh et al., 1998; Holtgraves, 1997; Li et al., 2000; Sanchez-Burks, 2005; Tjosvold \& Sun, 2003).

Together these literatures suggest the following culture by conflict type interaction hypothesis: The cultural differences between Americans and East Asians will be more pronounced for folk wisdom regarding the effects of relationship conflict compared to folk wisdom about task conflict. Americans should be more skeptical than Koreans or Chinese about the negative effects of perceived relationship conflict.

\section{Method}

\section{Participants}

Study participants were 136 European Americans $(68$ men and 68 women; age: $M=32.0$ years; $S D=2.2$ ), 80 Korean citizens ( 40 men and 40 women; age: $M=$ 31.8 years; $S D=3.1$ ), and 56 Chinese citizens $(28$ men and 28 women; age: $M=$ 32.8 years; $S D=2.8$ ) from a business graduate school at a large Midwestern university in the United States. Korean and Chinese participants arrived in the United States approximately 2 months prior to the study to begin graduate studies in business; none had prior experience of living in the United States. Participants completed the questionnaire survey as part of an in-class exercise. Gender and age were not significant covariates in any of the analyses. In addition, based on initial analyses showing no significant main effects or interactions between Korean and Chinese participants, data for these two groups were combined into one variable (East Asian). Participants completed materials in English; all Korean and Chinese participants had TOEFL scores greater than 600 and verbal GMAT scores greater than 37.

\section{Materials and Procedure}

Participants completed a survey in which they indicated their level of agreement with statements regarding the consequences of task and relationship conflict using a 5-point 
Likert scale $(-2=$ completely disagree, $+2=$ completely agree $)$. Importantly, these items were not intended to map directly onto items used in actual group studies (see De Dreu \& Weingart, 2003); rather they were designed to map onto beliefs about the consequences of two types of conflict defined in the literature. The terms "relationship conflict" and "task conflict" were defined at the top of the survey using Jehn and Chatman's (2000, p. 57) definitions of each conflict (see also Jehn \& Mannix, 2001) to orientate participants to the types of conflict referred to in the literature. These definitions read: "Relationship conflict involves disagreements based on personal and social issues that are not related to the team's work. Task conflict involves disagreements about the work that is being done within the team and is not related to personal and social issues." The conflict folk wisdom measure consisted of a 6-item relationship conflict belief scale (Cronbach's $\alpha=.74$ ) and a 6-item task conflict belief scale (Cronbach's $\alpha=.74$ ) that asked about the influence of each type of conflict. The items from these two scales were randomly interspersed throughout the survey. Example statements included: "Relationship (task) conflict is an absolute roadblock to a team accomplishing its work" and "Interpersonal friction (task conflict) does not necessarily get in the way of a team's performance" (reverse coded). (See the Appendix for the complete set of items.) Higher scores on each measure signaled agreement that conflict impairs group performance.

\section{Results}

Survey responses were analyzed using a Culture (European American vs. East Asian) $\times$ Conflict Type (Folk wisdom about Task Conflict vs. Folk wisdom about Relationship Conflict) mixed ANOVA, with conflict type as the within-subject variable. There was a main effect of Culture indicating that European Americans $(M=.40$, $S D=.74)$ compared to East Asians $(M=.70, S D=.76)$ were less likely to agree that conflict overall is detrimental to group performance, $F(1,270)=8.79, p<.01$. There also was a main effect of Conflict Type indicating that, overall, task conflict $(M=.62$, $S D=.77)$ was believed to be more detrimental to group performance than was relationship conflict $(M=.50, S D=.73), F(1,270)=4.59, p<.05$. These main effects were qualified, however, by a significant Culture by Conflict Type interaction, $F(1,270)=10.27, p<.01$, suggesting that European Americans differed from East Asians in their agreement concerning the consequences of perceived relationship conflict versus task conflict (see Figure 1).

As predicted, contrasts conducted for each type of conflict showed that European Americans $(M=.30, S D=.74)$ were significantly less likely than East Asians $(M=.69$, $S D=.62)$ to agree that relationship conflict is necessarily detrimental to task performance, $t(270)=4.57, p<.001$. However, with respect to task conflict, European Americans $(M=.62, S D=.74)$ were as likely as East Asians $(M=.63, S D=.80)$ to agree that conflict in this domain hampers group performance, $t(270)<1$. Within-culture contrasts further show that European Americans believed that relationship conflict was significantly less likely than task conflict to hamper group performance, $t(270)=3.92, p<.001$, whereas East Asians judged both types of conflict as having relatively equivalent effects, $t(270)<1$. 


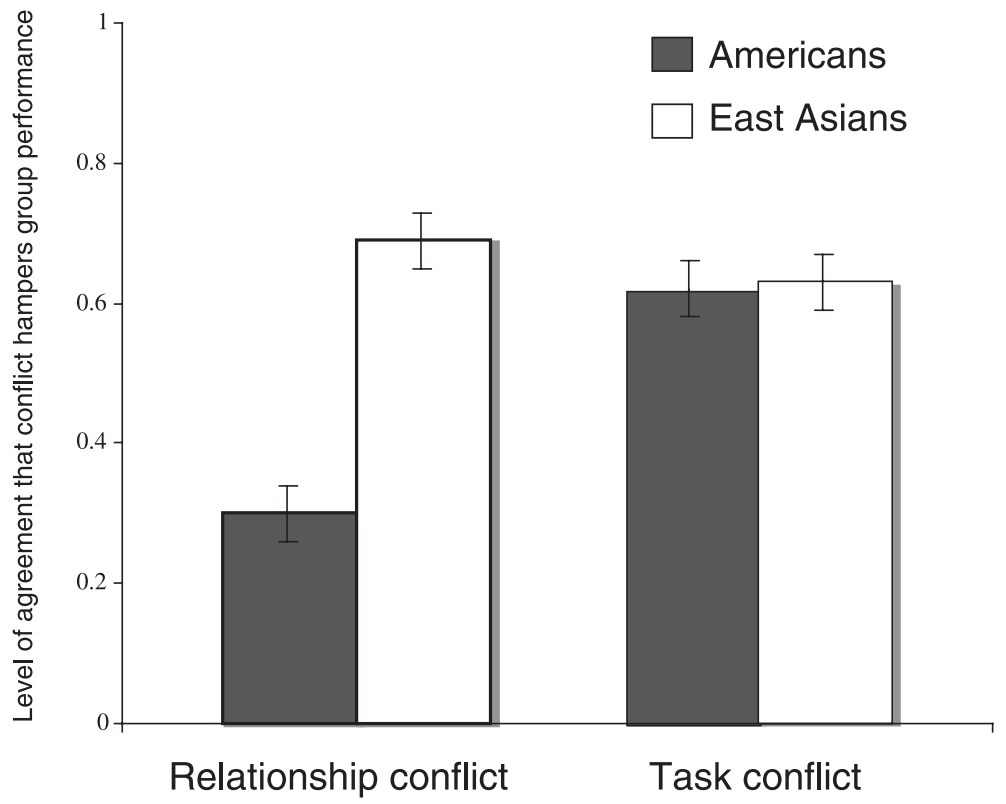

Figure 1. Folk wisdom about intragroup conflict as a function of conflict type and culture. Error bars represent one between-subjects standard error (Study 1).

\section{Discussion}

The results from Study 1 show that in contrast to East Asians, European Americans' folk wisdom about conflict showed greater optimism that group performance would not necessarily suffer because of intragroup conflict. In line with our theoretical predictions, this optimism about conflict was limited to conflict in the relational domain and not an overall cultural bias about conflict. Moreover, the pattern of results within and between cultures suggests a more complex cultural pattern of beliefs than simpler models of East-West main effect differences in group harmony might suggest (for a similar discussion, see Chen, Liu, \& Tjosvold, 2005; Tjosvold \& Sun, 2003; Tjosvold et al., 2005).

The findings highlight that East-West differences in folk wisdom about how conflict can harm group performance emerge only for certain forms of conflict-namely in the relational domain where European Americans generally place less importance in accordance with PRI. Complementary to prior PRI studies demonstrating restricted attention to relational concerns among Americans, these results show that even after making relational dynamics salient, their importance to the task at hand is discounted. Although this pattern cannot be attributed to cultural main effect differences in concern for minimizing conflict (Americans were as concerned as East Asians about conflict in the task domain), they might be plausibly attributed to differences in analytical and holistic thinking. Given the greater tendency in Americans toward analytical thinking and the 
greater tendency in East Asians toward holistic thinking (Nisbett, Peng, Choi, \& Norenzayan, 2001), Americans might be better able to distinguish the two types of conflicts than East Asians. For East Asians, greater holistic thinking may support the belief that, in practice, analytically categorizing conflict into task and relationship varieties is a false distinction. Study 2 was designed to address this potential limitation by testing whether members of both cultural groups similarly believed it made sense to distinguish between task and relational conflict.

\section{Study 2}

In the conflict literature, relationship and task conflict are differentiated in theory, measurement, and sometimes even empirically (De Dreu \& Weingart, 2003; Simons \& Peterson, 2000; Jehn \& Bendersky, 2003; Tidd et al., 2004). Many studies, including Study 1, provide participants with explicit definitions of the differences between task and relationship conflict. However, it is unclear whether these definitions from the literature conform to how well people from different cultural traditions perceive a difference between the nature of the two types of conflicts. It may be that East Asians, shown to use more holistic thinking, actually may disagree more than European Americans, shown to use more analytic thinking (Nisbett et al., 2001), that one form of conflict can be categorized as different or separate from the other. For East Asians, task conflict and relationship conflict may simply be two sides of the same coin. This would suggest that the relative optimism of European Americans concerning relational compared with task conflict found in Study 1 may not be valid support for our theoretical analysis, but instead be an unrelated artifact. Study 2 examines this issue directly by assessing the extent to which Americans and East Asians believe whether it is possible to differentiate relationship and task conflict.

In addition, Study 2 assesses whether East Asian and American study participants differ with respect to behavioral strategies for addressing these task and relational forms of conflict. Based on the findings of Study 1, we reasoned that an individual's motivation for task success would be reflected in a preference for resolving those forms of perceived conflict believed to be most detrimental to group performance. We hypothesized that European Americans compared to East Asians (in this study, specifically Koreans) would be less inclined to try to resolve perceived relationship conflict but would be equally likely to try to resolve task conflict.

\section{Methods}

\section{Participants}

The participants included 18 European Americans (13 men and 5 women; age: $M=31.1$ years; $S D=1.7$ ) and 12 Koreans ( 8 men and 4 women; age: $M=32.8$ years; $S D=4.2$ ) from a large Midwestern university. Gender and age were not significant covariates in any of the analyses. As in Study 1, participants completed all materials in English; all Korean participants had TOEFL scores greater than 600 and verbal GMAT scores greater than 37. 


\section{Materials and Procedure}

Participants completed three questions that were embedded in a larger general prescreening survey. The first item provided definitions of task and relationship conflict used in prior research (as described in Study 1) and then directly asked to what extent they agreed that in practice it is actually possible to differentiate relationship and task conflict. Specifically, to minimize demand characteristics, the question stated: "Although these definitions differentiate task conflict and relationship conflict, people often vary in how much they believe it is actually possible to separate these types of conflict. In your opinion, to what extent is it possible to separate relationship conflict and task conflict?" Two additional items asked participants to state their level of agreement with the following statements: "When task conflict arises, one should proactively try to resolve the task conflict" and "When relationship conflict arises, one should proactively try to resolve the relationship conflict. Responses were measured using a 7 -point Likert scale $(1=$ not at all, $4=$ do not know, $7=$ very much).

\section{Results}

\section{Differentiating Folk Wisdom About Relationship Conflict Versus Task Conflict}

We used a Culture $\times$ Conflict Type ANOVA to determine the degree to which participants agreed it was possible to make distinctions between the two types of conflict, followed by a sequence of planned contrasts. There was no support for the notion that European Americans more than Koreans perceive that it is possible to differentiate task and relationship conflict, as indicated by the lack of a main effect for Culture, $F(1,28)<1,[M s=4.73(1.27)$ vs. 5.23(1.42), respectively $]$.

The nature of the Likert scale used in this study provided a reference point from which it was also possible to assess meaningful levels of agreement versus disagreement on the question of whether these two forms of conflict could be conceptualized as distinct (i.e., midpoint represents "do not know"). Thus, we conducted contrasts separately for each group to examine whether they indicated an affirmation that the types of conflict were distinct that was significantly different from the midpoint response of "do not know" of the scale. These contrasts showed that both Koreans $[t(28)=12.30$, $p<.001]$ and European Americans $[t(28)=13.30, p<.001]$ significantly differ from the midpoint, indicating that it is possible to separate task and relationship conflict (Midpoint $=4$; European American $M=4.73(1.27)$, Korean $M=5.23(1.42)$ ). Thus, there is no support for the argument that the findings from Study 1 could have alternatively resulted from cultural differences in analytical (better able to distinguish, i.e., European American) versus holistic (less able to distinguish, i.e., East Asian) ways of thinking.

\section{Behavioral Intentions}

We analyzed participants' behavioral intentions for dealing with conflict using a Culture (European American vs. Korean) $\times$ Conflict Type (Folk Wisdom about Task Conflict vs. Relationship Conflict) mixed ANOVA, with folk wisdom about each type of conflict as 
the within participant variable. A main effect of culture indicated an overall greater agreement among Korean students $(M=5.73, S D=1.01)$ than European American students $(M=4.96, S D=1.60)$ that one should proactively try to resolve conflict in general, $F(1,28)=4.70, p<.05$. A main effect of conflict type indicated a stronger belief that one should resolve task conflict $(M=5.92, S D=1.20)$ than beliefs about resolving relationship conflict $(M=4.71, S D=1.70), F(1,28)=6.40, p<.05$. As predicted, however, there was a significant culture by conflict type interaction, $F(1,28)=4.50$, $p<.05$ (see Figure 2).

Whereas European Americans and Koreans were similar in their agreement that one should proactively try to resolve task conflict $[M s=6.00(1.31)$ vs. $5.82(1.10)$, respectively], $t(28)<1$, the European Americans were significantly less likely than the Koreans to agree the same effort should be put forth in trying to resolve relationship conflict $[M s=3.92(1.19)$ vs. 5.60(0.92), respectively], $t(28)=2.68, p<.05$. Moreover, a follow-up within culture contrast showed that European Americans indicated more disagreement with a proactive strategy for addressing relationship conflict than task conflict, $t(28)=2.70, p<.05$; Koreans showed no such difference $t<1$. Overall, European American participants' folk wisdom about conflict appears to place less importance on resolving relationship conflict than is the case for the Korean participants. Moreover, the European Americans place less importance on resolving relationship conflict than resolving task conflict. There were no other significant contrast effects.

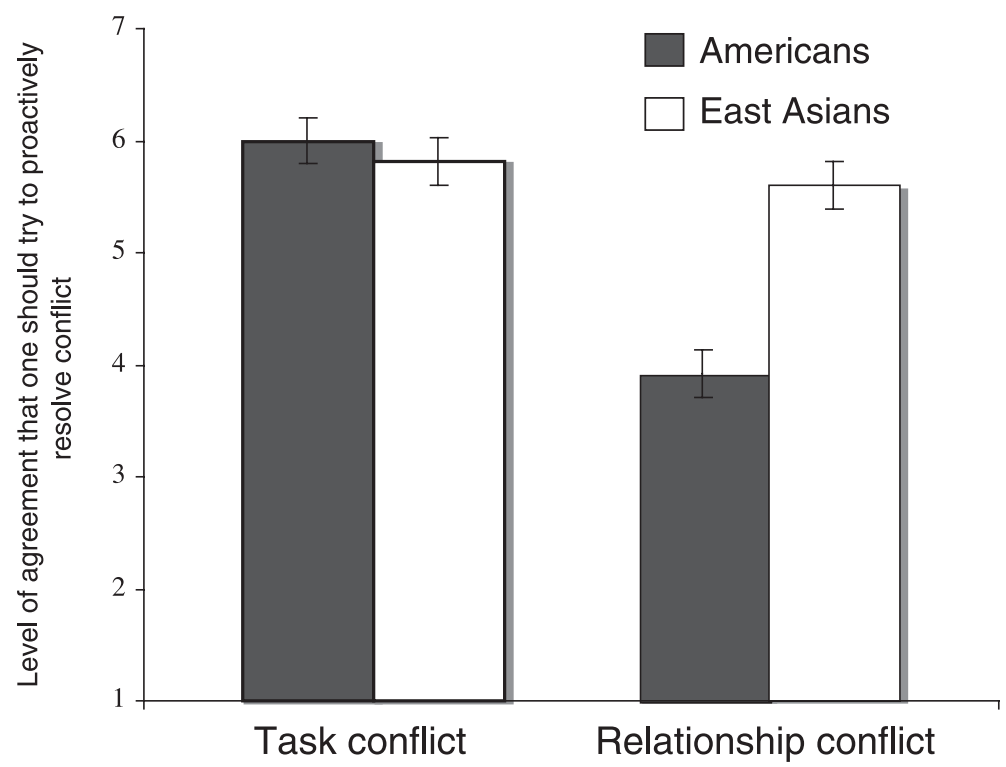

Figure 2. Behavioral strategies in response to group conflict as a function of culture and conflict. Error bars represent one between-subjects standard error (Study 2). 


\section{Discussion}

Consistent with scholarly efforts to conceptualize conflict focused on relational concerns as different from conflict focused on task concerns, Study 2 provides preliminary crosscultural support that study participants from the United States and Korea are familiar with these distinctions and their independent effects. This finding suggests that lay decision makers are as adept as conflict scholars at perceiving a difference between these types of conflict. Moreover, these data argue against the interpretation that Koreans' belief that both forms of conflict have negative consequences simply reflect their inability to understand how task and relationship conflict can operate independently.

Interestingly, Study 2 also provided evidence that both European Americans and Koreans would prefer to address and resolve task conflict proactively. Whereas Koreans also demonstrated a proclivity to address and want to resolve relationship conflict, European Americans did not. This result is consistent with the finding in Study 1 showing that European Americans did not believe relationship conflict hampers group performance. If one's folk wisdom suggests that relationship conflict does not present a threat to performance, as indicated by Study 1, then it may appear rational not to expend energy to address and resolve that type of conflict.

For participants who did indicate a motivation to intervene, there is an important limitation to Study 2 that relied on a single item to measure behavioral intentions to address conflict. This broad single item, for example, is unable to capture the type of conflict management strategy participants would prefer. A rich literature on this topic, including cross-cultural studies, has demonstrated important and subtle distinctions in preferred approaches for managing conflict that the present study is unable to capture. To the extent that individuals are more motivated to address conflict that is perceived as having substantive consequences compared to conflict that is considered inconsequential, future research might fruitfully examine how preferred conflict styles might vary as a function of folk wisdom about conflict and the type of conflict that emerges in the situation.

In general, the nature of the cultural variation appears to occur within the domain of relationship conflict. In both Studies 1 and 2, Americans and East Asians appear to hold similar beliefs and show similar behavioral strategies with respect to task conflict, but they consistently differ with respect to relationship conflict. The question we address in Study 3 is whether this pattern of beliefs would likewise influence the decision of European Americans and East Asians to join groups that are potentially ridden by high task or relationship conflict.

One methodological limitation of this research endeavor that has yet to be addressed is that the data for Studies 1 and 2 were collected from participants currently living in the United States, such that European Americans' folk wisdom was assessed in an intracultural setting (on their own turf), whereas beliefs and preferences of the East Asians who participated may have been shaped by their experiences as a visitor in a foreign country. Moreover, completing these measures in a foreign context may have brought that to mind for the East Asian participants working in groups with Americans. For Koreans, relationship conflict may be considered less important within Korea compared to such an intercultural context. That is, the heightened concern for interpersonal 
harmony (in both task and relationship domains) exhibited by the Korean and Chinese participants in Studies 1 and 2 might differ from how they perceive the consequences of conflict in their native culture. To empirically address this issue, in Study 3 we sought to replicate the conflict folk wisdom and preference results with a sample of Koreans living in their native society (i.e., Seoul, Korea).

Study 3 further addresses concerns that the cultural differences in folk wisdom about relationship conflict could be impacted by differences in language competencies between European American and East Asian study participants. To address this concern beyond controlling for a minimum English language competency (i.e., minimum TOEFL and verbal GMAT scores), Study 3 used a translated version of the materials for Korean participants.

\section{Study 3}

The primary goal of Study 3 was to examine further how PRI folk wisdom about conflict corresponds to behavioral intentions in conflict situations. Specifically, we tested how European Americans versus Koreans indicated they would react to situations where relationship conflict is likely to occur in a group. European Americans and Koreans were asked to consider how they would respond to an offer to join a team that is both technically talented and also highly likely to experience relationship conflict. Building on earlier findings showing that for Americans relationship conflict is not necessarily detrimental to group performance, we hypothesized European Americans compared with Koreans would be more likely to accept the invitation to join the group. Conversely, given the earlier findings indicating that relationship conflict is of greater concern to Koreans than to European Americans, suggesting that for Koreans, relationship conflict is perceived to more clearly negate the technical talents of the team, we hypothesized Koreans more than European Americans would not join such a team. A condition in which technical talent was held constant but where there was no indication of relationship conflict was included in the experimental design to provide a baseline comparison for evaluating within and between cultural patterns in decisions regarding these workgroup offers.

\section{Method}

\section{Participants}

The participants included 76 European American (42 men and 34 women; age: $M=25.0$ years; $S D=5.0$ ) and 85 Korean (55 men and 30 women; age: $M=23.0$ years; $S D=3.9)$ students from large universities in the United States and Korea. Participants completed the study as part of an in-class exercise. Gender and age were not significant covariates in any of the analyses.

\section{Materials and Procedure}

Folk Wisdom About Relationship and Task Conflict Study participants completed the same conflict folk wisdom survey as described in Study 1. The Korean version of all 
materials was developed and translated from English by a Korean member of the research team and then back translated by an independent individual to ensure conceptual equivalence of the constructs and items (Weldon \& Jehn, 1995). No major discrepancies were identified; all minor discrepancies were discussed and resolved to ensure conceptual equivalence. To control for the unintended influence that completing the conflict beliefs scale might have on responses to the vignettes described below, the scale was administered after participants had completed the survey.

Vignettes Describing an Offer to Join a Workgroup Participants received at random one of two versions of a vignette in which they were to imagine themselves faced with a decision about joining a new work group. ${ }^{1}$ Both versions began with the following preamble:

Imagine that you work for a flexible matrix organization where most projects last 6-8 months. Your current project will end in 4 weeks. The organization allows for some autonomy in choosing projects, and traditionally you meet with your manager and lock in your next project 2 weeks before rolling off your current project. You value project success, thus you care that the next one is successful. Before you meet with your manager, you receive an e-mail from Pat, the project leader of one of the upcoming projects. Pat has heard about you from your current project leader and wants you to join the team in his area. Although the group will be starting small, Pat says that if development goes well, the group will expand within 9 months and will be looking for people to assume team lead roles. Pat also believes your skill set nicely complements two other people who will be joining the team: Chris, who has a strong background in operations, and Terry, who can offer important finance skills. Bottom line, this collection of people brings to the table a high level of skill in areas critical for task success on the project. As you learn more about the project, you find out you will have to work with Chris and Terry very closely on a daily basis. During your time with the organization, you have met them once or twice, but have never worked on a project with either of them.

In one version (henceforth referred to as the "no relationship conflict," or NRC, condition), we told participants they anticipated getting along well with Chris and Terry.

Yet based on these encounters, you get the sense the group will get along very well. You can picture the three of you getting together when you are not working on the project, and you are highly confident you will have a really good time working together.

In the other version (the "relationship conflict," or RC, condition), we told participants their team would not get along well socially.

Yet based on these encounters, you get the sense the group will not click socially. You cannot picture the three of you getting together when you are not working on the project, and you believe the group is likely to have disagreements on personal/social issues, although not necessarily on anything related to the project.

\footnotetext{
${ }^{1}$ The vignette as well as the rest of the questionnaire was presented to participants in their native language. For the Korean versions, this included replacing the English names with common Korean names.
} 
Finally, both versions concluded with the manager asking the participant for a decision.

Due to the strong need to fill this position, Pat would like your decision within the next

2 days on whether you will join this project. Deciding by this deadline, however, would mean making a decision before you know about other possible projects. Thus, you have to decide whether to join Pat's group or see if there is another group you would prefer to join.

The design of the vignette portion of the experiment was a 2 (Conflict condition: RC vs. NRC) $\times 2$ (Culture: European Americans vs. Koreans) between-subject factorial. After reading one of the vignettes, participants indicated whether they would join the team $(1=$ Yes, $2=$ No $)$.

\section{Results}

\section{Conflict Folk Wisdom}

Participants' beliefs and expectations about conflict were analyzed through a Conflict Type $\times$ Culture mixed ANOVA. Neither the main effect of Conflict Type $(p=.55)$ nor Culture $(p=.11)$ was significant. However, consistent with the results of Study 1 , the interaction between Conflict Type and Culture was significant, $F(1,159)=26.76$, $p<.001$, showing that European American students differed from Korean students in their relative expectations concerning the consequences of relationship versus task conflict. Contrasts conducted for each type of conflict confirmed the predicted pattern, with European Americans $(M=.24, S D=.61)$ significantly less likely than Koreans $(M=.73, S D=.58)$ to believe that relationship conflict is necessarily detrimental to task performance, $t(159)=5.27, p<.001$. However, with respect to task conflict, European Americans $(M=.56, S D=.78)$ were as likely as Koreans $(M=.34, S D=.79)$ to agree that conflict in this domain hampers a team's performance, $t(159)=1.74, p=\mathrm{ns}$. Contrasts conducted within each culture show that whereas Koreans rated the consequences of relationship conflict as more harmful than those of task conflict, $t(159)=4.15, p<.01$, the opposite was true for European Americans, who were significantly less likely to agree that relationship conflict was as harmful as task conflict, $t(159)=3.18, p<.01$.

\section{Behavioral Intent}

Finally, we examined participants' ultimate willingness to join groups likely (versus unlikely) to experience relationship conflict through chi-square analyses conducted on participant's yes-or-no decisions. As hypothesized, and consistent with the notion that European Americans are optimistic that relationship conflict will not hamper performance, European Americans were significantly more willing than Koreans to join a talented group likely to experience relationship conflict (55.9\% vs. $25.6 \%$, respectively), $\chi^{2}(N=77)=7.33, p<.05$. However, European Americans and Koreans did not significantly differ in their willingness to join a talented group unlikely to experience relationship conflict $\left(71.4 \%\right.$ vs. $52.4 \%$, respectively), $\chi^{2}(N=84)=3.23, p>.05$. 


\section{Discussion}

Study 3 provided an initial test of the behavioral effect of the European American optimistic bias about relationship conflict. The scenario presented to participants represented a dilemma for those skeptical about the causal link between relationship conflict and task performance. Our results suggest that European Americans were less sure of this link relative to Koreans, which suggests a folk wisdom that a team's performance on task objectives is not inextricably tied to its ability to get along. European Americans were as certain as Koreans about the negative influence that task conflict can have on workgroups. This interaction between culture and type of conflict is consistent with prior cross-cultural studies showing a greater cultural divide in workplace cognition and behavior within the interpersonal domain (Sanchez-Burks \& Lee, 2007). Although Study 1 suggested that Koreans believed task and relationship conflict were, in relative terms, equally detrimental to group performance, Study 3 showed a stronger belief that relationship conflict is actually more detrimental-a pattern opposite to that exhibited by Americans. In addition, whereas Study 1 suggested Americans were overall more optimistic than Koreans about the likely effects of conflict, Study 3 showed that this optimism was limited specifically to relationship conflict. Together these results suggest that European Americans' folk wisdom about relationship conflict differs (a) from their beliefs about task conflict, (b) from results of prior meta-analyses on actual effects of relationship conflict, and (c) from the folk wisdom of conflict exhibited by East Asians.

\section{General Discussion}

This research contributes to an emerging theoretical and empirical literature on culture and beliefs about conflict (e.g., Adair, Brett, \& Okumura, 2001; Kray \& Haselhuhn, 2007; Morris \& Gelfand, 2004) by testing cultural similarities and differences in folk wisdom about the effects of relationship conflict. Across three cross-cultural studies on folk wisdom about relationship conflict versus task-focused conflict, we found evidence consistent with PRI theory's proposition that relational concerns in work contexts may be diminished for European Americans. European Americans were as likely as East Asians to perceive that task-focused conflict hampers team task performance, but showed less conviction that relationship conflict could be similarly detrimental. When juxtaposed to prior empirical research on the effects of team conflict, this American folk wisdom shows an optimistic bias regarding the consequences of perceived relationship conflict.

This cultural asymmetry in beliefs about relationship conflict is consistent with the American culture's relational ideology wherein the relational dimension is regarded as less relevant in work settings (Sanchez-Burks, 2005) and the East Asian tradition of emphasizing the importance of this dimension in work settings as much (or more) than in nonwork social settings (Hampden-Turner \& Trompenaars, 1993). The consistent pattern of cultural similarities with regard to folk wisdom about task-focused conflict further suggests that folk wisdom about conflict varies more in the relational domain than in the task domain (e.g., Tjosvold \& Sun, 2003; Tjosvold et al., 2005). Results from Study 2 suggest it is unlikely that the lack of an optimistic bias for Koreans reflected a 
reluctance or inability to agree with distinctions made between relationship and task conflict. In fact, both Koreans and European Americans showed similar agreement that each could be perceived as distinct.

This article provides initial evidence that suggests that cultural folk wisdom about conflict corresponds to a priori behavioral strategies for joining or not joining groups. In hypothetical group situations with both technical talent and a high potential for relationship conflict, East Asians showed behavioral intentions that reflected a strong belief that the talent would be completely offset by the conflict: They were more likely to avoid such groups. European Americans, on the other hand, were more willing to join a talented team that would likely experience relational turmoil, consistent with their expectations that such conflict would not necessarily be detrimental to the group's ability to succeed.

Different from prior research on PRI theory, the present research relied on selfreported assessments of relational importance. For example, where in earlier studies PRI was measured by assessing relative attention to task versus relational information (e.g., Sanchez-Burks, 2005), the present research measured PRI by assessing beliefs about the importance of relational versus task dynamics. In this way, the present study contributes empirically to the notion that American work culture can be characterized by both restricted attention and importance given to the relational domain of workplace interactions.

An important caveat and potential limitation of this approach to measuring the influence of a cultural ideology is the lack of a more general self-report PRI measure. In lieu of such a measure, PRI researchers have relied on multiple cognitive and behavioral indicators based on the assumption that these provide more direct measurement of cultural ideologies and that individuals would not or could not accurately introspect about their diminished relational attunement in work settings. The present studies suggest that at least for very specific dynamics such as relational conflict, self-report measures PRI-related beliefs can successfully be used. Nonetheless, a growing body of cross-cultural research suggests self-report measures of general cultural values can be highly problematic (Heine, Lehman, Peng, \& Greenholtz, 2002; Oyserman, Coon, \& Kemmelmeier, 2002; Peng, Nisbett, \& Wong, 1997). Recently, Morris and colleagues (Chiu, Morris, Hong, \& Menon, 2000; Fu et al., 2007), have demonstrated a promising alternative to self-report measures of broad cultural constructs; an approach that involves measuring or manipulating psychological states that moderate the influence of prevailing cultural values and ideologies on individual cognition and behavior (e.g., need for closure).

This article focused on folk wisdom regarding perceived conflict with preliminary investigations into behavioral intentions. A limitation of behavioral intention research in this domain is that while people may have reported their beliefs about how they would decide and react to groups likely to experience conflict, their actual behavior may be different. In future research it would be worthwhile to examine the similarities and differences in the way other cultural groups process and respond to perceived task and relationship conflict. Despite the relatively small sample size, significant cross-cultural differences were identified; but other cultures should be examined and empirical investigations should be extended to actual behavior. Additional research on this topic could 
provide insights needed to develop proactive strategies that culturally diverse teams can adopt to improve their task performance.

The belief among the cultural groups in this study is that task conflict is highly likely to reduce team performance. This belief, however, may limit the opportunity to learn first hand that the causal link between task conflict and performance can in fact be moderated, for example, by increasing group trust (Peterson \& Behfar, 2003; Simons \& Peterson, 2000). The findings further suggest that although virtually every study on the topic finds that perceived relationship conflict impairs group performance, this may not always be the case for every workgroup if each member of the team does not expect it to be necessarily harmful. This outlook, at least on the part of some group members, may help preclude a team from undergoing relationship conflict that facilitates a slowdown in performance independent of the initial severity of the conflict. Thus, there may be a way for teams to achieve task performance goals even when interpersonal discord exists. Such possibilities are illustrated in studies by De Dreu and Van Vianen (2001) and Murnighan and Conlon (1991), which suggest groups can reduce the negative effects of relationship conflict on performance by essentially "agreeing to disagree" and by striving to maintain as little attention to relational concerns as possible-at least until the task is completed. Future research might fruitfully explore the conditions under which diversity in beliefs about relationship conflict can be mitigated by this attitude versus when it will result in conflict about who is correct about the effects of conflict, what might be referred to as meta-conflict.

An example of the benefits of maintaining a divide between task and relational concerns while in the midst of relationship conflict is found in the collaboration of Gerth and Mills during their translation of Weber's work into English (Weber, 1947)—a book that, ironically, includes an analysis of American's low relational focus at work. Their collaboration yielded the following correspondence:

"It's a pity, Mills, that our glorious rows finally have come to the unglorious end. Unable to follow to the glorious heights of your moral elevation, I look forward to seeing you vanish in the snow white peaks of your moral Olympus. And now to business," he continued, without hesitation or explanation. Description of a letter from Hans H. Gerth to C. Wright Mills, February 19, 1945. (Oakes \& Vidich, 1999, p. 45)

This passage illustrates an interesting juxtaposition of the existence of interpersonal friction between work partners and their ability to achieve joint success. Although purely anecdotal, our findings suggest it would be unlikely that Mills or Gerth would have continued with the collaboration if they had believed their interpersonal animosity would hinder the success of their translation. For some people, it may appear perplexing as to how a relationally tumultuous collaboration could nevertheless be highly successful. But our findings suggest that it would appear quite plausible to many European Americans; even if people do not get along, they still should be able to focus on their jobs and accomplish task objectives (a sentiment echoed in Bernstein, ClarkeStewart, Roy, \& Wickens, 1997). Despite having a belief that is at odds with existing empirical research, societies in which people are more optimistic about a group's ability to prevail despite relationship conflict could be more likely to take a chance on 
collaboration with warning signs of interpersonal discord, given the collaboration has the right talent.

That Americans' folk wisdom about conflict differs from empirical findings to date appears both intuitive and puzzling. Findings of beliefs that are at odds with independent observations are not uncommon, but it is ironic that the culture most often sampled in studies that document the negative effects of relational conflict is the very group least likely to have corresponding beliefs; therein lies the paradox of this American optimism.

\section{References}

Adair, W., Brett, J., \& Okumura, T. (2001). Negotiation behavior when cultures collide: The United States and Japan. Journal of Applied Psychology, 86(3), 371-385.

Amabile, T. M., Conti, R., Coon, H., Lazenby, J., \& Herron, M. (1996). Assessing the work environment for creativity. Academy of Management Journal, 39(5), 1154-1184.

Amason, A. C. (1996). Distinguishing the effects of functional and dysfunctional conflict on strategic decision making: Resolving a paradox for top management teams. Academy of Management Journal, 39(1), 123-148.

Amason, A. C., \& Sapienza, H. J. (1997). The effects of top management team size and interaction norms on cognitive and affective conflict. Journal of Management, 23, 495-516.

Ambady, N., Koo, J., Lee, F., \& Rosenthal, R. (1996). More than words: Linguistic and nonlinguistic politeness in two cultures. Journal of Personality and Social Psychology, 70(5), 996-1011.

Bellah, R. N., Madsen, R., Sullivan, W. M., Swidler, A., \& Tipton, S. M. (1996). Habits of the heart: Individualism and commitment in American life (Updated ed.). Berkeley: University of California Press.

Bernstein, D. A., Clarke-Stewart, A., Roy, E. J., \& Wickens, C. D. (1997). Psychology (4th ed.). New York: Houghton Mifflin.

Chen, F., Liu, C., \& Tjosvold, D. (2005). Conflict management for effective top management teams and innovation in China. Journal of Management Studies, 42(2), 277-300.

Chiu, C.-Y., Morris, M. W., Hong, Y.-Y., \& Menon, T. (2000). Motivated cultural cognition. The impact of implicit cultural theories on dispositional attribution varies as a function of need for closure. Journal of Personality and Social Psychology, 78(2), 247-259.

Clark, M., \& Mills, J. H. (1993). The difference between communal and exchange relationships: What is and is not. Personality and Social Psychology Bulletin, 19(6), 684-691.

Coser, L. (1956). The functions of social conflict. Glencoe, IL: Free Press.

Cosier, R. A., \& Rose, G. L. (1977). Cognitive performance and goal conflict effects on task performance. Organizational Behavior and Human Performance, 19, 378-391.

De Dreu, C. K. W., \& Van Vianen, A. E. M. (2001). Managing relationship conflict and the effectiveness of organizational teams. Journal of Organizational Behavior, 22(3), 309-328.

De Dreu, C. K. W., \& Weingart, L. R. (2003). Task versus relationship conflict, team performance, and team member satisfaction: A meta-analysis. Journal of Applied Psychology, 88(4), 741-749. 
DeVoe, S. E., \& Iyengar, S. S. (2004). Managers' theories of subordinates: A cross-cultural examination of manager perceptions of motivation and appraisal of performance. Organizational Behavior and Human Decision Processes, 93(1), 47-61.

Doucet, L., \& Jehn, K. (1997). Analyzing harsh words in a sensitive setting: American expatriates in communist China. Journal of Organizational Behavior, 18, 559-582.

Earley, P. C. (1993). East meets West meets Mideast: Further explorations of collectivistic and individualistic work groups. Academy of Management Journal, 36(2), 319-348.

Evan, W. (1965). Conflict and performance in R\&D organizations. Industrial Management Review, 7, 37-46.

Farh, J. L., Tsui, A. S., Xin, K. R., \& Cheng, B. S. (1998). The influence of relational demography and guanxi: The Chinese case. Organization Science, 9(4), 471-488.

Fischer, D. (1989). Albion's seed: Four British folkways in America. New York: Oxford University Press.

Fiske, A. P., Kitayama, S., Markus, H. R., \& Nisbett, R. E. (1998). The cultural matrix of social psychology. In D. T. Gilbert, S. T. Fiske \& G. Lindzey (Eds.), The handbook of social psychology (4th ed., Vol. 2, pp. 915-981). Boston: McGraw-Hill.

Fu, J., Morris, M. W., Lee, S.-L., Chao, M., Chiu, C.-Y., \& Hong, Y.-Y. (2007). Epistemic motives and cultural conformity: Need for closure, culture, and context as determinants of conflict judgments. Journal of Personality and Social Psychology, 92(2), 191-207.

Furnham, A. (1990). The Protestant work ethic: The psychology of work related beliefs and behaviours. New York: Routledge.

Gabrielidis, C., Stephan, W. G., Ybarra, O., Pearson, V. M. D., \& Villareal, L. (1997). Preferred styles of conflict resolution-Mexico and the United States. Journal of Cross-Cultural Psychology, 28(6), 661-677.

Gelfand, M. J., \& Brett, J. M. (Eds.) (2004). The handbook of negotiation and culture. Stanford, CA: Stanford University Press.

Gelfand, M. J., Higgins, M., Nishii, L., Raver, J., Dominguez, A., Yamaguchi, S., et al. (2002). Culture and egocentric perceptions of fairness in conflict and negotiation. Journal of Applied Psychology, 87(5), 833-845.

Gelfand, M. J., Nishii, L. H., Dyer, N., Holcombe, K. M., Ohbuchi, K. I., \& Fukuno, M. (2001). Cultural influences on cognitive representations of conflict: Interpretations of conflict episodes in the United States and Japan. Journal of Applied Psychology, 86(6), 1059-1074.

Guetzkow, H., \& Gyr, J. (1954). An analysis of conflict in decision-making groups. Human Relations, 7, 367-382.

Hampden-Turner, C., \& Trompenaars, A. (1993). The seven cultures of capitalism: Value systems for creating wealth in the United States, Japan, Germany, France, Britain, Sweden, and the Netherlands. New York: Doubleday.

Heine, S., Lehman, D., Peng, K., \& Greenholtz, J. (2002). What's wrong with cross-cultural comparisons of subjective Likert scales?: The reference-group effect. Journal of Personality and Social Psychology, 82(6), 903-918.

Holtgraves, T. (1997). Styles of language use: Individual and cultural variability in conversational indirectness. Journal of Personality and Social Psychology, 73(3), 624-637.

Hui, C., \& Luk, C. (1997). Industrial/organizational psychology. In J. Berry, M. Segall \& C. Kagitcibasi (Eds.), Handbook of cross-cultural psychology (Vol. 3, pp. 371-412). Needham Heights, MA: Allyn \& Bacon. 
Jehn, K. A. (1995). A multimethod examination of the benefits and detriments of intragroup conflict. Administrative Science Quarterly, 40(2), 256-282.

Jehn, K. A., \& Bendersky, C. (2003). Intragroup conflict in organizations: A contingency perspective on the conflict-outcome relationship. Research in Organizational Behavior, 25, 187-242.

Jehn, K., \& Chatman, J. (2000). The influence of proportional and perceptual conflict composition on team performance. International Journal of Conflict Management, 11(1), 56-73.

Jehn, K., \& Mannix, E. (2001). The dynamic nature of conflict: A longitudinal study of intragroup conflict and group performance. Academy of Management Journal, 44(2), 238-251.

Jehn, K. A., Northcraft, G. B., \& Neale, M. A. (1999). Why differences make a difference: A field study of diversity, conflict, and performance in workgroups. Administrative Science Quarterly, 44(4), 741-763.

Jehn, K. A., Rupert, J., \& Nauta, A. (2006). The effects of conflict asymmetry on mediation outcomes: Satisfaction, work motivation, and absenteeism. International Journal of Conflict Management, 17(2), 96-109.

Kim, S. U. (1988). The role of social values and competitiveness in economic growth: With special reference to Korea. In D. Sinha \& H. S. R. Kao (Eds.), Social values and development: Asian perspectives (pp. 76-92). Thousand Oaks, CA: Sage.

Kray, L., \& Haselhuhn, M. (2007). Implicit negotiation beliefs and performance: Experimental and longitudinal evidence. Personality and Social Psychology Bulletin, 93(1), 49-64.

Lenski, G. (1963). The religious factor: A sociological study of religious impact on politics, economics and family life. Garden City, NY: Anchor Books.

Li, J. T., Tsui, A. S., \& Weldon, E. (2000). Management and organizations in the Chinese context. New York: Palgrave Macmillan.

McNeill, J. T. (1954). The history and character of Calvinism. Oxford: Oxford University Press.

Morris, M. W., \& Gelfand, M. J. (2004). Cultural differences and cognitive dynamics: Expanding the cognitive perspective on negotiation. In M. J. Gelfand \& J. M. Brett (Eds.), The handbook of negotiation and culture (pp. 45-70). Stanford, CA: Stanford University Press.

Murnighan, J. K., \& Conlon, D. E. (1991). The dynamics of intense work groups: A study of British string quartets. Administrative Science Quarterly, 36, 165-186.

Nemeth, C. J. (1986). The differential contributions of majority and minority influence. Psychological Review, 93, 23-32.

Nisbett, E., Peng, K., Choi, I., \& Norenzayan, A. (2001). Culture and systems of thought: Holistic versus analytic cognition. Psychological Review, 108(2), 291-310.

Oakes, G., \& Vidich, A. J. (1999). Collaboration, reputation, and ethics in American academic life: Hans H. Gerth and C. Wright Mills. Urbana, IL: University of Illinois Press.

Oyserman, D., Coon, H. M., \& Kemmelmeier, M. (2002). Rethinking individualism and collectivism: Evaluation of theoretical assumptions and meta-analyses. Psychological Bulletin, 128(1), 3-72.

Pelled, L. H. (1996). Relational demography and perceptions of group conflict and performance: A field investigation. International Journal of Conflict Management, 7, 230-246.

Peng, K., Nisbett, R. E., \& Wong, N. (1997). Validity problems comparing values across cultures and possible solutions. Psychological Methods, 2(4), 329-344.

Peterson, R. S., \& Behfar, K. J. (2003). The dynamic relationship between performance feedback, trust, and conflict in groups: A longitudinal study. Organizational Behavior and Human Decision Processes, 92(1-2), 102-112. 
Pinkley, R. L. (1990). Dimensions of conflict frame-Disputant interpretations of conflict. Journal of Applied Psychology, 75(2), 117-126.

Rahim, M. A., Antonioni, D., Krumov, K., \& Ilieva, S. (2000). Power, conflict and effectiveness: A cross-cultural study in the United States and Bulgaria. European Psychologist, 5(1), $28-33$.

Sanchez-Burks, J. (2005). Protestant relational ideology: The cognitive underpinnings and organizational implications of an American anomaly. In B. M. Staw \& R. M. Kramer (Eds.), Research in organizational behavior (Vol. 26, pp. 267-308). New York: Elsevier.

Sanchez-Burks, J., \& Lee, F. (2007). Cultural psychology of workways. In S. Kitayama \& D. Cohen (Eds.), Handbook of cultural psychology (pp. 346-369). New York: Guilford Press.

Sanchez-Burks, J., Lee, F., Choi, I., Nisbett, R., Zhao, S., \& Koo, J. (2003). Conversing across cultures: East-West communication styles in work and non-work contexts. Journal of Personality and Social Psychology, 85(2), 363-372.

Sanchez-Burks, J., Nisbett, R. E., \& Ybarra, O. (2000). Cultural styles, relational schemas, \& prejudice against outgroups. Journal of Personality and Social Psychology, 79(2), $174-189$.

Simons, T. L., \& Peterson, R. S. (2000). Task conflict and relationship conflict in top management teams: The pivotal role of intragroup trust. Journal of Applied Psychology, 85(1), 102-111.

Smith, P. B., Peterson, M. F., \& Schwartz, S. H. (2002). Cultural values, sources of guidance, and their relevance to managerial behavior: A 47-nation study. Journal of Cross-Cultural Psychology, 33, 188-208.

Tidd, S., McIntyre, H., \& Friedman, R. (2004). The importance of role ambiguity and trust in conflict perception: Unpacking the task conflict to relationship conflict linkage. International Journal of Conflict Management, 15(4), 364-380.

Tinsley, C. H., \& Brett, J. M. (2001). Managing workplace conflict in the United States and Hong Kong. Organizational Behavior and Human Decision Processes, 85(2), 360-381.

Tjosvold, D. (1991). The conflict-positive organization. Boston: Addison-Wesley.

Tjosvold, D., Poon, M., \& Yu, Z. (2005). Team effectiveness in China: Cooperative conflict for relationship building. Human Relations, 58(3), 341-367.

Tjosvold, D., \& Sun, H. (2003). Openness among Chinese in conflict: Effects of direct discussion and warmth on integrative decision making. Journal of Applied Social Psychology, 33(9), 1878-1897.

Tocqueville, A. D. (1840/2003). Democracy in America (G. E. Bevan, Trans.). London: Penguin.

Triandis, H. C., Marin, G., Lisansky, J., \& Betancourt, H. (1984). Simpatia as a cultural script of Hispanics. Journal of Personality and Social Psychology, 47, 1363-1375.

Wall, V. D., \& Nolan, L. L. (1986). Perceptions of inequity, satisfaction, and conflict in task-oriented groups. Human Relations, 39(11), 1033-1051.

Weber, M. (1904). Protestant ethic \& the spirit of capitalism. Winchester, MA: Allen \& Unwin. Weber, M. (1947). The theory of social and economic organization (T. Parsons, Trans.). New York: Free Press.

Weldon, E., \& Jehn, K. (1995). Examining cross-cultural differences in conflict management behavior: A strategy for future research. International Journal of Conflict Management, 6(4), 387-403. 


\section{Appendix}

Relationship Conflict Folk Wisdom Measures

1. To predict a team's likely success in completing a difficult project, one does not necessarily need to know about the team members' ability to get along. (R)

2. Relationship conflict is an absolute roadblock to a team accomplishing its work.

3. For a team to complete a job successfully, they must first focus their attention on resolving relationship conflict before moving forward on the project.

4. Relationship conflict gets in the way of a team's potential to complete a task successfully.

5. Interpersonal friction does not necessarily get in the way of a team's performance. (R)

6. Relationship conflict necessarily limits a team's potential to achieve success on a project.

Task Conflict Folk Wisdom Measures

1. To predict a team's likely success in completing a difficult project, one does not necessarily need to know about the team members' ability to agree on the task. (R)

2. Task conflict is an absolute roadblock to a team accomplishing its work.

3. For a team to complete a job successfully, they must first focus their attention on resolving task conflict before moving forward on the project.

4. Task conflict gets in the way of a team's potential to complete a task successfully.

5. Disagreement about the task does not necessarily get in the way of a team's performance. (R)

6. Task conflict necessarily limits a team's potential to achieve success on a project.

Note. $\mathrm{R}$, reverse coded.

Karen Goh (mgoh@marshall.usc.edu) received her PhD from the Marshall School of Business at the University of Southern California. Her research focuses on culture and team dynamics.

Shirli Kopelman (shirli@bus.umich.edu) is an assistant professor of management and organization at the Ross School of Business at the University of Michigan. She received a $\mathrm{PhD}$ in management and organizations from the Kellogg School of Management at Northwestern University and has a BA in psychology from The Hebrew University of Jerusalem. Her research focuses on individual and group decision-making in social dilemmas, factors promoting cooperation in interdependent intra- and inter-organizational contexts, strategic display of emotions, negotiation strategy, and cross-cultural differences in approaches to conflict management and resolution.

Eric J. Neuman (eneuman@umich.edu) is a doctoral candidate in Management and Organizations at the Ross School of Business at the University of Michigan. His research focuses on understanding the relationship between institutional change and organizational behavior. His dissertation examines state-level variation in entrepreneurship following deregulation of the local telephone industry in 1996.

Hyekyung Park (hparkz@umich.edu) is a doctoral student in social psychology at the University of Michigan. Her research focuses on the cultural and cognition of the self and interpersonal relationships. 
Jeffrey Sanchez-Burks (jsanchezburks@umich.edu) is an assistant professor of management and organizations at the Ross School of Business at the University of Michigan in Ann Arbor. He received his $\mathrm{PhD}$ in Social Psychology from the same university. His research focuses on how interactions, relationships, and leadership can be maximized in a global economy by understanding differences in how people interpret social emotional aspects of work; currently he is investigating how leaders come to understand the emotional landscape of their organization (referred to as a leader's emotional aperture), and the factors that facilitate versus inhibit this collective emotion recognition.

Oscar Ybarra (oybarra@umich.edu) is an associate professor of psychology in the Department of Psychology at the University of Michigan, Ann Arbor. He received his $\mathrm{PhD}$ in social psychology from New Mexico State University. His research focuses on how people judge and behave toward others and make decisions about their social surroundings, issues he studies in the context of intergroup relations and conflict, cultural influences on behavior, and distrust and unpredictability during social interaction. 